\title{
Improving quality of health care: the role of pharmacists
}

\author{
Nick Barber, Felicity Smith, Stuart Anderson
}

This is the second article in the occasional series in which health professionals discuss the contribution of their specialty to quality of patient care.

Pharmacists are society's experts on drugs. They have been at the interface between prescribers and patients for centuries: in the community particularly they have long provided a direct service to the public. For most of this time they have made medicines and advised on their use, but the growth of the pharmaceutical companies - under increasingly stringent legislation - has removed much of the need for local manufacturing and quality control. Pharmacists' traditional roles of compounding medicines and dispensing prescriptions have been replaced with activities requiring the full range of their training and skills, ranging from avoiding drug interactions and detecting adverse reactions to giving advice and monitoring drug treatment. Pharmacists now have many varied new roles, sometimes called pharmaceutical care, to respond to the changing needs of the public, to changes in health care objectives, and to changes in health service delivery.

The role and potential role of pharmacists in the community (retail pharmacy) and in hospitals have been set out in several documents and reports. ${ }^{1-6}$ The World Health Organisation has recently called on pharmacists to support its drug strategy and has urged governments to define the role of pharmacists and to make full use of their skills in national drug strategies. ${ }^{7}$ The independent Nuffield enquiry into pharmacy in 1986 encouraged the growth of the clinical advisory role in community and hospital, ${ }^{1}$ as did a health circular for hospital pharmacy in $1988 .^{2}$ Four years later a joint report of the Department of Health and the Royal Pharmaceutical Society

Centre for Pharmacy Practice,

School of Pharmacy, University of London, London WC1N $1 A X$ Nick Barber, professor Felicity Smith, lecturer Stuart Anderson, lecturer Correspondence to: Professor Barber
Economical and efficient procurement and supply of medicines

Preparation and assembly of medicines as needed

Safe and secure storage and efficient distribution of medicines

Facilitating the safe, effective, and economic use of medicines, including advice to doctors in relation to the selection and dosage of medicines

Monitoring the quality of medicines

Providing comprehensive and continuous pharmaceutical care, including the interface with general practitioners and community pharmacists

Controlling the medicines' budget

Box 1 Care functions of hospital pharmacy services ${ }^{8}$ of Great Britain recommended ways in which community pharmacy should develop in the United Kingdom. ${ }^{3}$

Although pharmacists working in hospitals and in the community are committed to ensuring the safe, effective, and economic use of medicines, the activities of the two groups differ in style and emphasis. Two of the key differences are access to the prescriber and degree of professional isolation. Hospital pharmacists work in close proximity to medical staff, who are normally readily accessible. They have an important role in advising junior doctors on prescribing and on writing prescriptions. Most hospital pharmacists also have the benefit of working alongside colleagues who can advise and support them. For community pharmacists contact with the prescriber is not always easy, and many work in relative professional isolation. A third role for pharmacists is developing in scope and importance - that of adviser to commissioning agencies (district health authorities and family health services authorities).

The core functions of hospital pharmacy services have been described by the National Association of Health Authorities and Trusts (NAHAT) ${ }^{8}$ and are summarised in box 1 . The extended role of community pharmacists has been outlined by the Royal Pharmaceutical Society (box 2). ${ }^{9}$ In addition, an increasing number of pharmacists now work for commissioning agencies, and the pharmaceutical

1 Delivery services to household patients

2 Services for groups with special needs

3 Services for residential homes

4 Out of hours services

5 Domiciliary visits

6 Hospital discharge and admission procedures

7 Health promotion activities

8 Needle and syringe exchange schemes

9 Distribution of welfare food

10 Disposal of unwanted medicines

11 Sale of prepayment certificates

12 Health screening

13 Patient referrals to general practitioners and other health professionals

14 Development of local formularies

15 Provision of professional advice

16 Advice on palliative care

17 Supply of disability aids

18 Reporting adverse drug reactions

19 Provision of quiet area for confidential conversations

20 Supply of complementary medicines

21 Advice on over the counter medicines

22 Training of other health professionals

Box 2 Extended role of community pharmacists ${ }^{\circ}$ 
1 Strategic planning including pharmaceutical input into needs assessment of local population

2 Pharmaceutical aspects of public health

3 Pharmaceutical input into contracting for secondary and tertiary care

4 Primary care commissioning issues, ensuring community pharmacists make a full contribution to health gain

5 Effectiveness and clinical audit

6 Developing a purchasing strategy for special pharmaceutical support services

7 Pharmaceutical input into statutory inspection functions for nursing and residential homes

8 Advising on the pharmaceutical aspects of policies for care in the community

Box 3 Pharmaceutical functions of commissioning agencies"

functions of these have also been described by NAHAT (box 3). ${ }^{8}$ These three boxes give a flavour of the diversity of roles and of activities currently undertaken by pharmacists. In this paper we will consider the roles of community and hospital pharmacists separately.

\section{Community pharmacy}

Pharmacists have a long and distinguished history of presence in the community for the supply of drugs, both in accordance with prescriptions from medical practitioners and as part of their advice to people with minor ailments (so called counter prescribing). Upheavals in community and primary care in recent years have probably had less direct impact on pharmacists than on other health professionals. However, pharmacists are aware that they must respond to these changes and are keen to do so; they are now identifying areas in which they can enhance the quality of patient care in line with current health care objectives and the government's priorities for the delivery of health care. These changes have presented new challenges for pharmacists. Not only do they need to adapt their roles to respond to these changes but they also need to monitor and evaluate the services they offer.

The potential of community pharmacists as primary health professionals has so far not been fully exploited. These changes are being encouraged by financial incentives. Community pharmacists are independent practitioners contracted to the family health services authorities in England and Wales and to the health boards in Scotland and Northern Ireland. They are remunerated for their NHS services principally on the basis of the number of prescriptions dispensed, although in recent years the basis for the remuneration has diversified; they now receive separate payments for services to residential homes and for maintaining computer based records of drug treatment for their regular clients. In the future the basis of remuneration may be restructured to encourage diversification of their role in serving current health care objectives, such as giving advice and promoting health. The money will be provided by reducing dispensing fees. Currently, Scotland is taking a lead on this.
All community pharmacies are staffed by a registered pharmacist, who is present on the premises during all opening hours. This pharmacist will have undertaken a similar education and training (three year degree course and one year of preregistration training) to that of pharmacists in other branches of the profession.

RISSPNDINC; 10 SYMPTONS

An average pharmacist advises around 10 people daily on the management of minor ailments."112 This amounts to over 100000 people daily across the country, or 30 million a year - a number which is thought to be increasing and unlikely to fall. Increased client interest and concern about drug use will lead to more demand from pharmacists for advice. Their role in advising people with minor ailments is as old as the profession, and pharmacists are a readily available source of advice, as they are usually immediately available to clients who need advice. Pharmacists are well aware of the need to show quality in these services, and they have been forced to acknowledge this need by the scrutiny of their role in responding to minor ailments by outside organisations. ${ }^{1 / 1}$

Several of these investigations have attracted much media attention, and pharmacists have recently embraced professional audit. Many studies have been performed on the quality of advice offered by pharmacists. Methods and findings have been mixed, and some causes for concern have been uncovered. ${ }^{15}$ in Smith et al concluded, however, that, although a third of community pharmacists gave very poor advice, half of them gave very good advice. ${ }^{15}$ These issues are being addressed by pharmacists to ensure higher standards of care in the future. Despite the long tradition of pharmacists advising on minor ailments it is only recently that education and training for this role has become a substantial part of the undergraduate curriculum and an important feature of postgraduate education. The increasing number of drugs that have changed from prescription only medicines and have become readily available in pharmacies means that more clients will go to their local pharmacy first. This may also increase the proportion of visits to medical practitioners that are referrals from a pharmacist.

PRESCRIBED I RUGS

The quality of prescribing needs to be assessed, and good treatment still needs to be monitored - roles for which pharmacists are ideally placed. They can detect inadvertent changes in prescriptions for medicines, check for possible adverse drug reactions, and discuss any other problems with the treatment that the client may have. Dispensing prescriptions is probably the most well known function of community pharmacists; it is the most important activity financially and accounts for a large proportion of their time. Pharmacists are, therefore, centrally placed to monitor drug treatment. Research has highlighted inadequate monitoring of drug 
treatment in the community - for example, high incidences of adverse drug reactions and potential drug interactions. Elderly people - a rapidly rising proportion of the population are particularly at risk. Adverse drug reactions are estimated to account for at least $10 \%$ of hospital admissions in elderly people. ${ }^{17}$ Many pharmacists now keep records on computer for their regular clients taking drugs long term to enable them to monitor closely their clients' drug treatment. As more prescription only drugs become available without a prescription, this monitoring role will become more important. It will also become increasingly likely that symptoms which are drug related will arise, though they may not always be identified as such by the client. Community pharmacists are well placed to identify such effects and to advise the patient accordingly.

The poor level of prescribing and drug treatment in many residential and nursing homes is well known. In many states in the United States every nursing home must by law be visited by a consultant pharmacist once a month to review the clinical appropriateness of all prescribing. We may need to act similarly in the United Kingdom, and domicilary visits by pharmacists have unearthed more drug related problems.

Pharmacists believe that they have an important part to play in promoting adherence to (or compliance with) drug treatment by reenforcing the prescribing instructions or helping sort out problems by recommending different formulations or drugs. Poor adherence to treatment frustrates many prescribers: it is estimated that only about $50 \%$ of clients take their drugs as and when intended. ${ }^{18}$ Reasons for lack of adherence are many, ranging from a lack of understanding or dislike of the taste to doubts about the appropriateness of prescriptions and fears (or experience) of adverse effects. Home visits by pharmacists allow the drugs to be discussed with the patient, side effects to be identified, and problems to be sorted out.

\section{DISEASE PREVENTION AND HEALTH}

\section{PROMOTION}

Community pharmacists are ideally placed to provide disease prevention and health promotion services in line with the government's priorities. ${ }^{19}$ Many people, representing a broad cross section of the population, visit pharmacies every day. The potential of these visits for health promotion activities has been developed since the inquiry into pharmacy conducted by the Nuffield Foundation ${ }^{1}$ and also the government's white paper Promoting Better Health. ${ }^{6}$

Pharmacists have opportunities to discuss disease prevention and health promotion when clients request advice on managing minor ailments. Some pharmacies also display health promotion literature and take part in local initiatives such as advising on immunisation, first and second line treatments for hair infestation, giving up smoking, and needle exchange schemes for intravenous drug misusers.

Privacy is an important aspect of quality of care. If pharmacists are to develop their advisory role, then discussions with clients about their problems with over the counter medicines must clearly take place in a private area set aside for this purpose. The profession is aware of the need for privacy if clients are not to be inhibited from raising their concerns and pharmacists are not to be inhibited from discussing sensitive issues in consultations. Private areas are also useful for discussing prescription drugs with clients. The development of suitable consultation areas is being encouraged and paid for in some family health services authorities.

\section{TEAMWORK}

Pharmacists have an important role within the primary health care team. Although they usually work separately from other members of the team, what they do with their clients is a clear extension of the work that starts in the general practitioner's surgery. The relative isolation in which many pharmacists work, and the fact that they work on premises distinct from the rest of the other health professionals, mean that they are sometimes considered to be only on the fringes of the primary health care team. Although pharmacists are required to be on the pharmacy premises during opening hours, there are, nevertheless, many opportunities for meaningful collaboration between them and other primary health care professionals and for regular contact between them, both by telephone and in person.

Community pharmacists share their clients with other practitioners and need to develop these links, not only with prescribers but also with others such as district nurses, health visitors, specialist nurses in the community, physiotherapists, chiropodists, dentists, and occupational therapists. Some pharmacists work with general practitioners on practice formularies, prescribing practices, the interpretation of prescribing analysis and cost (PACT) data, and the review of drugs as part of a home visit. However, there are matters of concern to all health professions - for example, the appropriate use of benzodiazepines, on which communication is currently minimal. ${ }^{20}$ Both pharmacists and doctors recognise the need to address this problem, to advise clients about appropriate use, to monitor for misuse, and to be prepared to discuss reducing doses when asked. There is growing concern about the participation in issues such as this by members of the two professions, and there is increasing discussion and awareness of the other's activities and contribution to the health of the community.

\section{Hospital pharmacy}

THE PAST 30 YEARS

The role of hospital pharmacists has shown remarkable development over the past 30 years and is a major influence on prescribing and drug use. Many factors have contributed to this. For example, during this time drug treatment has become both more effective and more complex. In the late 1960s high numbers of drug administration errors were discovered 
in hospitals. ${ }^{21} 22$ Systems that entailed drug charts and pharmacists visiting wards were shown to be effective and were subsequently recommended for implementation in all hospitals in the Gillie report. ${ }^{*}$

These changes led to pharmacists seeing patients and being more clinically involved. In the 1970s many hospital pharmacies introduced drug information centres, and the application of pharmacists' knowledge to the wellbeing of the patient became known as clinical pharmacy. In 1988 a health circular on the way forward for hospital pharmacy services set out the roles of pharmacy in hospitals and the ways pharmacy should be promoted in several clinical areas. ${ }^{2}$ The changes were recommended for implementation without additional funding as they were expected to be self financing from economies resulting from better drug use.

IMPROVING PRESC:RIBING;

In hospitals pharmacists are well recognised as a useful source of advice on prescribing. This is now an extensive service; over one week in North West Thames Region there was about one intervention for every three acute beds and over 3000 prescriptions were changed on the advice of pharmacists. ${ }^{23}$ This has extended naturally into a wider role in medical and clinical audit. ${ }^{21}$ 2o The core of pharmacists' contribution to appropriate prescribing and drug use is the ward pharmacy service, in which pharmacists visit wards - usually daily to check the drug charts of all patients in order to clarify any ambiguities, to initiate supply of these drugs not stocked on the wards, and to intervene in the prescribing, supply, or administration processes wherever necessary. Pharmacists will also check that any intravenous lines are running correctly. In effect, this activity represents a constant audit of prescribing. A great deal of information is used in monitoring prescribing besides the drug chart, including talking to patients, observing patients, reading the information available at the end of the bed, and looking in the notes if necessary. ${ }^{27}$ Several studies in the United Kingdom and United States show that doctors readily accept the suggestions of pharmacists. $^{28-32}$ Pharmacists' interventions relate to the whole range of prescribing, many being concerned with the choice of drug, dose, and route of administration. When judging the appropriateness of prescribing other factors also come into play, including the effectiveness of the drug, its cost, and the effect on the quality of life of the patient. Unfortunately, this activity is largely undocumented and unrecognised, and it tends to take place mainly between pharmacists and junior doctors.

In many hospitals at least one pharmacist will attend a consultant's round. There is little research on the contribution the pharmacist makes, but recent work suggests that the input is variable. Some simply act as an information source when asked a question, whereas on some specialist rounds, such as those of nutrition or pain teams, the pharmacist may offer around half the suggestions made to initiate, alter, or end treatment. ${ }^{33}$ The disadvantage of pharmacists being on rounds is that much of the round may be of little relevance to drug treatment, and it may be difficult to justify releasing a member of staff for three hours to make an active contribution for only 10 to 15 minutes. Attending rounds does have other advantages, however, particularly in helping pharmacists to understand the complexities of therapeutic decision making and in helping clinicians consider wider aspects of drug treatment (and in some cases to make medical staff consider drug treatment at all).

SPECIAIIS"I SERVICES

Several specialist hospital pharmacy services have been developed, although a recent census of hospital pharmacies in the United Kingdom showed appreciable differences in their availability. ${ }^{3+}$ There is some evidence that pharmacists are better than doctors in taking drug histories, as they tend to detect more drugs being taken and obtain additional information about the use of over the counter and herbal medicines. ${ }^{35}$ This pharmacy service has not been widely available in the past, but it may develop when analysis of interventions shows that a poor drug history causes problems. For example, it is not uncommon for about a third of interventions in orthopaedic wards to be due to incorrect clerking and prescription writing on admission. Pharmacists are also commonly active in pain control in terms of producing drugs, filling devices, and giving advice on the choice of treatment and dose. ${ }^{38}$

Therapeutic drug level monitoring reporting the concentration of a drug in the blood and using pharmacokinetic calculations to recommend a new dose and frequency - is commonly practised as part of the hospital pharmacy service. 30 " Audits have shown that over half the samples taken are inappropriate. ${ }^{+1+2}$ Some hospital pharmacies now offer a complete service: they are given the name of the patient and they take the blood, measure the drug concentration, and advise on any alterations to the dosing regimen. At some sites pharmacists also run warfarin clinics. ${ }^{13}$ it Special adverse drug reaction monitoring schemes have been successful, and pharmacists might be able to report such reactions directly to the Committee on Safety of Medicines in due course..$^{15}$ to

Hospital pharmacists also contribute to the economic aspects of drug use - controlling purchasing costs and working with clinicians on formularies, treatment protocols, review and evaluation of drug use, and medical and clinical audit. ${ }^{4 i-50}$ At the core of these activities is information from computerised purchasing and dispensing systems and information brought back from the wards by pharmacists. These roles are coming together in the provision of advice to directorates, and clinical directors are increasingly tending to pay their own pharmacists to provide these services.

\section{The future}

The future of pharmacy is inextricably linked with the future of medicines. The continuing 
high cost of drugs will ensure the growing importance of pharmacoeconomics. Downward pressures on drug costs will shave the margins of industry and wholesalers, and new technology will change the purchasing and supply stucture. For pharmacy the emphasis will be on a "value added" supply service, with much of the value being in providing information and monitoring quality. Although some of this can be undertaken by computers, there are limitations to this, and there is no substitute for contact with patients. The development of new drugs through biotechnology will lead to difficulties in formulation and administration that will keep pharmacists challenged and involved. The increase in domiciliary care will also make home visits and "closed door" pharmacies common, perhaps leading to competition between hospital and community pharmacists. The effect of market forces on newly established NHS trusts is already forcing reductions in the number of hospital pharmacists, a quarter of senior posts having already gone. ${ }^{51}$ The danger is that this may lead to a reduced quality of service at some sites. Both purchasers and trusts need to set firm quality standards to ensure that pharmacy services to not become stagnated or atrophied. In community practice the law requiring pharmacists to remain on the premises at all times creates constraints in further developing the role of pharmacists. One possible development is to have more than one pharmacist in each pharmacy so that a wider range of services both inside and outside the pharmacy can be more effectively pursued.

\section{Conclusion}

Pharmacists have responded positively to health service changes and to developments in drug treatment. They make a substantial contribution to the overall quality of health care by ensuring that the prescriber's intentions are translated into the safe, effective, and economic use of medicines; that the prescribers themselves have the information necessary to make such decisions; and that patients have the information they need to obtain maximum benefit from their treatment.

Although there are clearly ways in which improvements can be made, the profession of pharmacy can move forward in the knowledge that the benefits of a pharmaceutical service provided by highly educated, motivated, and accessible professional people is well recognised, not only by its clients but also by doctors and by those making policy decisions. It can grasp the many opportunities available to it in the future, including the new roles of the commissioning agencies, with confidence and enthusiasm.

1 Committee of Inquiry. Pharmacy: the report of a committee of inquiry appointed by the Nuffield Foundation. London: Nuffield Foundation, 1986

2 Department of Health. Health services management: the way forward for hospital pharmaceutical services. London: Department of Health, 1988. (HC $(88) 54$.)

3 Joint Working Party on the Future Role of the Community Pharmaceutical Services. Pharmaceutical care: the future for community pharmacy. London: Royal Pharmaceutical Society of Great Britain, 1992.
4 Department of Health and Social Security. Measures for controlling drugs on the wards. London: DHSS, 1970. (Gillie report.)

5 Department of Health. Guidelines for the safe and secure handling of medicines: a report to the Secretary of State for Health. London: Department of Health, 1988. (Duthie report.)

6 Secretary of State for Health. Promoting better health. London: HMSO, 1987. (Cmd 249.)

7 World Health Organisation. Proceedings of the 48th World Health Assembly, Geneva, May 1994. Pharmaceutical fournal 1994;252:699.

8 National Association of Health Authorities and Trusts. The role of pharmaceutical advisers and managers and role of pharmaceutical advisers and managers and pharmacists in

9 Guidelines for managing changes in community pharmaceutical services. Pharmaceutical fourmal 1994; 253:817-20.

10 Boylan LJ. Advisory role of the pharmacist. Pharmaceutical foumal 1978;221:328.

11 D'Arcy PF, Irwin WG, Clarke D, Kerr J, Gorman W, O'Sullivan D. The role of the general practice pharmacist in primary health care. Pharmaceutical foumal 1980;223:539-42.

12 Smith FJ, Salkind MR. Factors influencing the extent of the pharmacist's advisory role in Greater London. Pharmaceutical foumal 1990;244:R4-7.

13 Consumers' Association. Advice across the chemist's counter. Which? 1985;8:351-4.

14 Consumers' Association. Pharmacists: how reliable are they? Which? Way to Health 1991;Dec:191-4.

15 Smith FJ, Salkind MR, Jolly BC. Community pharmacy: a method of assessing quality of care. Soc Sci Med 1990;31:603-7.

16 Anderson CW, Alexander AM. Response to dysmenorrhoea: an assessment of knowlege and skills. Pharmaceutical fournal 1992;249:R2

17 Williamson J, Chopin JM. Adverse reactions to prescribed drugs in the elderly: a multicentre investigation. Age Ageing 1980;9:73-80.

18 Becker $M H$. Patient adherence to prescribed therapies. Med Care 1985;23:539-55.

19 Secretary of State for Health. The health of the nation. London: HMSO, 1992. (Cmd 1986.)

20 Smith FJ. General medical practitioners and community pharmacists in London: views on the pharmacist's role and responsibilities relating to benzodiazepines. Fournal of Interprofessional Care 1993;7:37-45.

1 Vere DW. Errors of complex prescribing. Lancet 1965;i:370-3.

22 Crooks J, Clark CG, Caie HB, Mawson WB. Prescribing and administration of drugs in hospital. Lancet 1965; i: 373-8.

23 Barber ND, Batty R, Beech E. What do hospital pharmacists do on the wards? In: Social pharmacy: innovation and development. London: Pharmaceutical Press, 1994:159-73.

24 Davies G. Clinical audit: a new development. Pharmaceutical foumal 1989;HS30-1.

25 Harris SK, Smith FJ, Moss F. The pharmacist's contribution to medical audit: perceptions of doctors and pharmacists in the North West Thames Regional Health Authority. F Soc Admin Pharm 1993;10:36-41.

26 Anderson SC. Completing the clinical audit cycle: discharge medication. International fournal of Health Care Quality Assurance 1994;7:4-8.

27 Batty R, Barber ND. Prescription monitoring for ward pharmacists. Pharmaceutical fournal 1991;247:242-4.

28 Cousins D, Hatoum H. The development of computerised quality assurance system for clinical pharmacy. International fournal of Pharmacy Practice 1991;1:86-9.

29 Kennedy K, Wind K. The development of a monitoring package for pharmacy interventions. Hospital Pharnacy Practice 1992;2:93-100.

30 Klopfer JD, Einarson TR. Acceptance of pharmacists' suggestions by prescribers: a literature review. Hospital Pharmacy 1990;25:830-6.

31 Batty R, Barber N. Ward pharmacy: a foundation for prescribing audit? Quality in Health Care 1992;1:5-9.

32 Hawkey CJ, Hodgson S, Norman A, Daneshmend TK, Garner ST. Effect of reactive pharmacy intervention on the quality of hospital prescribing. BMF 1990;
300:986-90.

33 Fletcher PF. The contribution of the pharmacist to the ward round [MSc thesis]. London: School of Pharmacy,

34 Cotter S, Barber ND, McKee M. The provision of clinical pharmacy services in the United Kingdom. Am $\mathcal{f}$ Hosp Pharm (in press)

35 Higham C. Drug history taking - a role for the ward pharmacist. Pharmaceutical foumal 1982;228:302-5.

36 Gurwich EL. Comparison of medication histories acquired by pharmacists and physicians. Am $\mathcal{f}$ Hosp Pharm 1983;40:1541-2

37 Titcomb LC. The pharmacist's role in drug history taking. British fournal of Pharmaceutical Practice 1989; 11:186-95.

38 Taylor DM, Heath ML. Pharmacist involvement in the provision of patient controlled analgesia. Hospital Pharmacy in Practice 1992;2:623-8.

39 Blackbourne T, Sunderland VB. Impact of pharmacist interventions on oral theophylline therapy in adult patients. Drug Intell Clin Pharm 1987;21:811-6. 
4) Briceland LL, Nightingale CH, Quinfiliani R, Cooper BW, Smith KS. Antibiotic streamlining: from combination therapy to monotherapy utilising an interdisciplinary therapy to monotherapy utilising an interd
approach. Arch Intern Med 1988;148:2019-22.

41 Gibb I, Campbell-Cowan J, Parnham AJ, Thomas TH. Use and misuse of a digoxin assay service. BMF 1986; and misuse of a digoxin assay service. BMf 1986 ;

42 Elfellah MS, Doran JF, Grieve MS. Audit of digoxin monitoring in Tayside. Pharmaceutical foumal 1990; 244:726-7.

43 Simmons A. Run an anticoagulation clinic. Hospilal Pharmacy in Practice 1994;4:151-6.

44 Pegg M, Bourne J, Mackay AD, Lawton WA, Cole RB. The role of the pharmacist in the anticoagulant clinic. fR Coll Phwsicians. Lond 1985;19:39-43.

45 Slaughter R. Adverse drug reaction monitoring in hospitals: a study of a pharmacy monitoring scheme in the
Northern Region. Pharmacitical formal 1989; 243(suppl):R48. (Pharmacy practice.)

46 Lee A, Bateman DN, Edwards C, Smith JM. Adverse drug reaction reporting by hospital pharmacists. Phamacutical foumal 1993;251 (suppl):R19. (Pharmacy practice.)

47 Davies $G$, Lewis L. Clinical audit: a new development? Pharmaccutical foumul 1989;243(suppl):HS30 1. (Hospital pharmacy.)

18 Davey P, Dodd T Kerr S, Malek M Audit of is antibiotic administration. Pharmaciutical foumal 1990):244:293-0.

t9 Morgan DJR, Sutters CA Pugh S Medical audit and formulary managernent a policy for rational use of thrombolytic drugs. Postgrad Med f 1991;67:165-9.

50 Orme J, Shalford A, Barber ND, Schwart\% B. Quality of hospital prescribing. B.MF 1990;300:1398.

51 Anderson SC. Pharmacy's other crisis. P/atmaciutical foumal 1994:252:504.

8 